\title{
Variation in the phenology of shoot elongation between geographic provenances of maritime pine (Pinus pinaster) - implications for the synchrony with the phenology of the twisting rust fungus, Melampsora pinitorqua
}

\author{
ML Desprez-Loustau, F Dupuis \\ INRA, Centre de Bordeaux, Station de Pathologie Végétale, BP 81, \\ F-33883 Villenave-d'Ornon cedex, France
}

(Received 18 March 1993; accepted 17 December 1993)

\begin{abstract}
Summary - The phenology of shoot elongation was monitored for 2 or 3 years at 4 sites in France with 6 maritime pine geographic provenances. Within each provenance, the onset of phenological stages, especially the earlier ones, was better predicted by heat sums than by calendar days. The accuracy of prediction could be increased by about $50 \%$ for the earliest studied stage (from 19 to $10 \mathrm{~d}$ ). However, temporal and, to a greater extent, site effects were still observed for heat sums. These may be attributed in part to stressful environmental conditions for pine. The geographic provenances used represent a range of significantly different heat requirements, the Tamjout (from Morocco) and the Leiria (from Portugal) provenances representing the earliest and the latest, respectively, with a difference of approximately 100 degree-days (for a threshold temperature of $0^{\circ} \mathrm{C}$ ). A positive correlation was observed between precocity and vigour though this could not explain differences in precocity between provenances. A comparison of pine and rust (Melampsora pinitorqua) phenologies, monitored at the same sites in south-west France, revealed that synchrony between the host-susceptible stages and the parasite-spore-producing stages did not always occur. The earliness of the Tamjout provenance predisposed it to greater rust infection than other provenances due to better synchrony with basidiospore production. Variations in host-parasite synchrony are discussed from an evolutionary perspective and in relation to the prediction of infection risk.
\end{abstract}

maritime pine / rust / phenology / susceptibility period / infection risk

Résumé - Variabilité phénologique de l'élongation des pousses entre provenances géographiques de pin maritime. Conséquences sur la synchronisation avec la phénologie du champignon responsable de la rouille courbeuse, Melampsora pinitorqua. La phénologie d'élongation des pousses a été suivie pendant 2 ou 3 ans dans 4 sites pour 6 provenances géographiques de pin maritime. Pour chaque provenance, les sommes de températures et les dates ont été comparées en tant que variables prédictrices de l'apparition des stades phénologiques, par la méthode du coef- 
ficient de variation et de l'erreur standard de prédiction. Les sommes de températures se sont révélées les meilleures variables prédictrices, surtout pour le stade le plus précoce, avec une erreur de prédiction réduite d'environ 50\% (de 19 à 10 i). Toutefois, il reste une variation entre années et surtout entre sites. Cette dernière pourrait provenir en partie de conditions défavorables pour la croissance des pins dans 2 des sites étudiés. Les provenances étudiées ont manifesté des exigences thermiques significativement différentes, les provenances Tamjout (Maroc) et Leiria (Portugal) représentant la plus précoce et la plus tardive respectivement, avec une différence d'environ 100 degrés/jours (pour un seuil de $0^{\circ} \mathrm{C}$ ). La précocité et la vigueur sont corrélées positivement. Toutefois les différences de précocité entre provenances sont maintenues après ajustement à la vigueur. La sensibilité des pins et la phénologie du champignon responsable de la rouille courbeuse (Melampsora pinitorqua) ont été suivies dans le même site dans les Landes. La coïncidence entre les stades sensibles chez les pins et la production de basidiospores par le champignon n'est pas toujours observée, même pour la provenance landaise de pin maritime. La précocité de la provenance Tamjout se traduit par une plus grande prédisposition aux infections que pour les autres provenances, du fait de la coïncidence entre la période de sensibilité et la production de basidiospores. Une discussion est proposée sur les variations de la coïncidence phénologique hôte-parasite, du point de vue de l'évolution et en relation avec la prévision des risques d'infection.

\section{pin maritime / rouille / phénologie / période de sensibilité / risque d'infection}

\section{INTRODUCTION}

Maritime pine (Pinus pinaster Ait) shoot elongation has been studied extensively with respect to seasonal pattern (IIly and Castaing, 1968), genetic control (Kremer, 1982), and morphogenetic components (Kremer and Roussel, 1982, 1986; Kremer and Lascoux, 1987). However, most studies have focussed on quantitative aspects since they have concerned breeding for higher growth rates. The phenology of elongation has been given little attention as it often appears unrelated to total shoot growth (Cannell et al, 1976).

Our interest in phenological variation in maritime pine originates from an observation that such variation appeared to be associated with differences in susceptibility to twisting rust, caused by Melampsora pinitorqua Rostr (Desprez-Loustau and Baradat, 1991). Pine shoots show different degrees of susceptibility to $M$ pinitorqua according to their elongation stage, the maximum susceptibility being observed between bud-scale disjunction and needle emergence (Kurkela, 1973; Desprez-Loustau, 1990). Furthermore, the basidiospores causing infections are produced only for a short period in spring (approximately 1 month), after the breaking of teliospore dormancy (Kurkela, 1973; Desprez-Loustau and Dupuis, 1992). Therefore, variations in pine phenology may affect the synchrony between susceptible stages and basidiospore occurrence. The prediction of phenological stages in maritime pine may provide a risk assessment of rust infection, when related to the prediction of basidiospore dispersal.

The present study was undertaken with 2 objectives. The first was to confirm and define the extent of phenological variation in maritime pine: our previous data (DesprezLoustau and Baradat, 1991) were limited to a few measurements at a single site. We thus compared provenances originating from the whole natural distribution area of $P$ pinaster at 4 locations in France representing a wide range of environmental conditions. As air temperature has been shown to be a major determinant of shoot growth in many species including conifers (Lavender, 1980; Perala, 1985), we analysed thermal requirements at the onset of the different phenological stages for each maritime pine provenance. Pines were monitored from 3 to 
5 years old, at an age of fixed growth pattern (ie elongation of preformed units, Lanner, 1976) and with a high susceptibility to twisting rust. The second objective was to give further biological support to the previously observed relationship between phenology and rust infections in maritime pine. This part of the study was restricted to 1 site in the Landes area, where the fungus has a natural occurrence and the pine twisting rust disease is endemic. Rust phenology and rust susceptibility of 3 contrasting maritime pine provenances were monitored.

\section{MATERIALS AND METHODS}

\section{Experimental design}

Six geographic provenances of $P$ pinaster were compared. The main ecological characteristics of the seed collection sites are given in table I. In additon, 'hybrids' were created between the Landes and the Corsica provenances by pollination of 5 maternal trees from 1 provenance with the combined pollen from 10 paternal trees of the other. Reciprocal crossings were made by inversing maternal and paternal trees. All families obtained from the various crossings were used as [Corsica $\times$ Landes] hybrids.

Seedlings were grown in nursery for 1 year, and then transplanted in the experimental sites.

The general features of the 4 experimental sites are given in table II. Sixty plants per population (provenances or hybrids) were used at each site. The [Corsica $\times$ Landes] hybrids were not used at the Lagnereau site. Completely randomized designs with unit plots of 3-6 trees were used.

\section{Monitoring shoot elongation}

Weekly observations were performed in spring (March-June) for 2 successive years at each site ( 3 years at the Ruscas site). On each observation date, shoot length and phenological stage were recorded for each tree on the leader shoot. The phenological stages were defined according to Debazac (1966) (fig 1), as follows:

B0: dormant buds;

B1: buds swollen;

B2: buds elongating, disjunction of bud scales making the shoot surface visible;

Table I. Main ecological characteristics of seed collection sites.

\begin{tabular}{|c|c|c|c|c|}
\hline Site & Situation & Altitude & Climate & Soil \\
\hline Cuenca & Spain (east) & $1300 \mathrm{~m}$ & $\begin{array}{l}\text { Mediterranean, } \\
\text { humid }\end{array}$ & $\begin{array}{l}\text { Superficial, brown, } \\
\text { above sandstone }\end{array}$ \\
\hline Tamjout & Morocco (east) & $\begin{array}{l}1650 \mathrm{~m} \text { middle } \\
\text { Atlas }\end{array}$ & $\begin{array}{l}\text { Mediterranean, } \\
\text { semi-arid }\end{array}$ & $\begin{array}{l}\text { Superficial, brown, } \\
\text { above carbonated } \\
\text { sandstone }\end{array}$ \\
\hline Esterel & France (south-east) & $550 \mathrm{~m}$ & $\begin{array}{l}\text { Mediterranean, } \\
\text { humid }\end{array}$ & $\begin{array}{l}\text { Superficial, brown, } \\
\text { above standstone }\end{array}$ \\
\hline Landes & France (south-west) & $10-20 \mathrm{~m}$ & Oceanic & Podzolic, sandy \\
\hline Leiria & Portugal (north) & $50 \mathrm{~m}$ coast & Oceanic & Old dune \\
\hline Vivario & Corsica & $600 \mathrm{~m}$ & $\begin{array}{l}\text { Mediterranean, } \\
\text { humid }\end{array}$ & $\begin{array}{l}\text { Superficial, brown, } \\
\text { above siliceous rock }\end{array}$ \\
\hline
\end{tabular}


Table II. General features of experimental sites.

\begin{tabular}{|c|c|c|c|c|c|}
\hline Site & Situation & Climate & $\begin{array}{l}\text { Ecological } \\
\text { conditions }\end{array}$ & $\begin{array}{l}\text { Plantation date; } \\
\text { observation dates }\end{array}$ & $\begin{array}{l}\text { Experimental } \\
\text { design }\end{array}$ \\
\hline Lagnereau & $\begin{array}{l}\text { Gironde } \\
\text { (south-west) }\end{array}$ & Oceanic & Humid moor & $1986 ; 1989,1990$ & 3 trees/unit plot \\
\hline Truncat & $\begin{array}{l}\text { Gironde } \\
\text { (south-west) }\end{array}$ & Oceanic & $\begin{array}{l}\text { Dry coastal } \\
\text { dune }\end{array}$ & $1986 ; 1989,1990$ & 5 trees/unit plot \\
\hline Ruscas & $\begin{array}{l}\text { Var } \\
\text { (south-east) }\end{array}$ & $\begin{array}{l}\text { Mediterranean, } \\
\text { humid }\end{array}$ & $\begin{array}{l}\text { Plateau, sandy } \\
\text { soil }\end{array}$ & $\begin{array}{l}1986 ; 1988,1989 \\
1990\end{array}$ & 6 trees/unit plot \\
\hline Orleans & Loiret (centre) & $\begin{array}{l}\text { Semi-continental } \\
\text { with oceanic } \\
\text { influence }\end{array}$ & $\begin{array}{l}\text { Presence of } \\
\text { hydromorphy }\end{array}$ & $1988 ; 1991,1992$ & 3 trees/unit plot \\
\hline
\end{tabular}

B3: emergence of brachyblasts;

B4: emergence of needles;

$\mathrm{B} 5$ : disjunction of the needles from the same fascicle

Owing to the acropetal development of shoots, observations were made at approximately the L/3 level from the shoot base; $L$ is defined as the shoot length on the observation date. The date of occurrence of a phenological stage was considered to be the date when this stage was first observed.

\section{Phenology of M pinitorqua}

Samples of infected aspen leaves, the overwintering host of $M$ pinitorqua, were collected on each observation date near the Lagnereau and Ruscas sites in 1989 and 1990. The developmental stage of the fungus was defined as its potential to produce basidiospores under optimal conditions in the laboratory, as described previously (Desprez-Loustau and Dupuis, 1992). The period extending from maximum production to the end of production under these conditions was shown to coincide with basidiospore dispersal under field conditions.

\section{Shoot susceptibility tests}

Shoots from the last whorl level were collected from 3 provenances (Landes, Tamjout and

Vivario) on 5 dates in 1989 and 1990 at the Lagnereau experimental site. Inoculations were performed on excised shoots under controlled conditions, using basidiospore producing aspen leaf discs, as described previously (Desprez-Loustau, 1990). Mean basidiospore numbers per inoculated shoots were approximately 10000 (350 per $\left.\mathrm{mm}^{2}\right)$ in 1989 and 5000 (180 per $\left.\mathrm{mm}^{2}\right)$ in 1990. Successful inoculations (ie shoots bearing pycnia and/or aecia) were assessed after 3 weeks.

\section{Meteorological data}

Minimum and maximum daily temperatures recorded at the nearest standard climatological station (National Meteorological Network) were used for each site. Heat sums (HS), in degreedays, were calculated according to the following formula:

$$
H S=\sum_{i}\left(T m_{i}-T t\right)
$$

for days with $T m_{j}>T t, T m_{i}=$ mean daily temperature, calculated as $T m=(T \min +T \max ) / 2$ or assuming a sinewave diurnal fluctuation between $T \min$ and $T \max ; T t=$ threshold temperature.

Each degree from 0 to $5^{\circ} \mathrm{C}$ was tested, as this range includes values commonly used for shoot growth studies (Cannell and Smith, 1983; Osawa et al, 1983; Perala, 1985; Volney and Cerezke, 1992). 

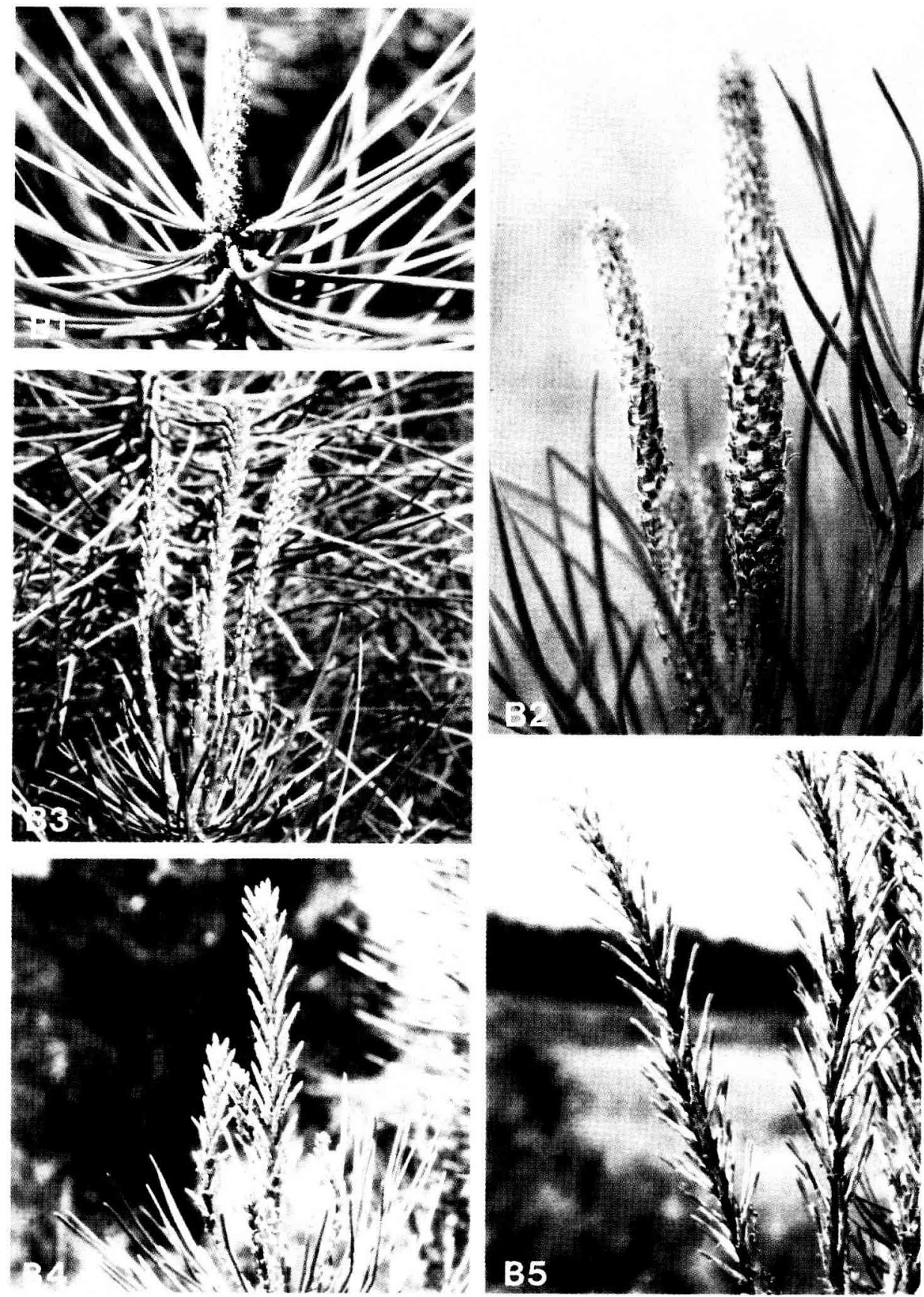

Fig 1. Phenological stages of maritime pine shoots, according to Debazac (1966): B1: buds swollen; B2: buds elongating, disjunction of bud scales making the shoot surface visible; B3: emergence of brachyblasts; B4: emergence of needles; B5: disjunction of the needles from the same fascile. 
The cummulative degree-day values were always calculated from January 1 of each year.

\section{Statistical analysis}

Calendar days and the different heat sums, obtained with the aforementioned formula, were compared as predictors of the onset of phenological stages. Two statistical approaches, the coefficient of variation and the standard error of prediction were used (Castonguay et al, 1984). First, the mean of individual tree values was calculated for the different tested variables in each of the 9 [site $x$ year] combinations of the study, for each stage and each provenance. The coefficients of variation $(\mathrm{CV})$, ie the ratio of the mean to the standard deviation of these 9 values, were then calculated. The approach using the standard error of prediction is based on the comparison between observed and predicted dates of the onset of phenological stages. Predicted dates were obtained as follows. For calendar days, the predicted value, taken for 1 given provenance and 1 given stage, was the mean date observed over the 9 [site $x$ year] combinations. For heat sum variables, the predicted dates were obtained by determining, in each of the 9 [site $x$ year] combinations the date corresponding to the mean heat sum value previously calculated from the 9 observed values from their respective meteorological data. The error of prediction was calculated as the difference between the predicted and actual dates. The mean value of these errors over the 9 [site $x$ year] combinations should be null. The standard deviation represents the standard error of prediction (Castonguay et al, 1984). The best predictor variables should present low values of both coefficient of variation and the standard error of prediction.

Phenological data were analysed by analysis of variance with the SAS package (SAS Institute, 1988). Means per unit plot, comprising 3-6 trees, were considered as elementary data. As the same trees were observed in the successive years (resulting in an inherent correlation of measurements between years), repeated measures analysis of variance were performed, using a multivariate approach (Moser et al, 1990). The non-violation of the assumptions of the analysis of variance, particularly the adequacy of the model and the homogeneity of residual variances, were checked graphically by plotting residuals against predicted values and examining the distribution of intra-group variances.

Infection percentages were analysed using a generalization of the analysis of variance adapted to categorical data analysis (CATMOD procedure of SAS). A log-linear model, with a maximumlikelihood estimation of the parameters, was used.

\section{RESULTS}

\section{Pine phenology}

The mean dates of occurrence, all provenances being pooled, of the different phenological stages for the 9 [site $\times$ year] combinations are given in table III. The phenological evolution of the Landes provenance at the Lagnereau site in 1989 and 1990 is presented in figure 2 as an example. A range of about $40 \mathrm{~d}$ was observed between sites for the same stage. As expected, pine development occurred much later in the northern site (Orleans) than in the 3 southern ones. Variation within any given site over the 2- to 3-year observation period was less than between sites.
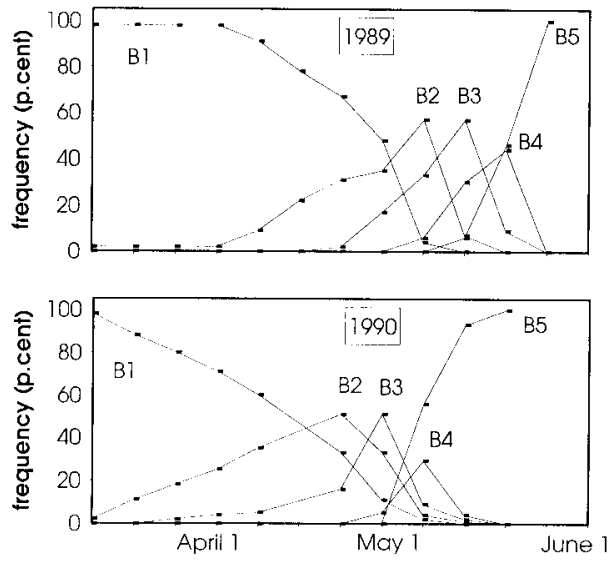

Fig 2. Phenological evolution of the Landes provenance of maritime pine at the Lagnereau site in 1989 and 1990. 
Table III. Mean dates of occurrence of the phenological stages of maritime pines, all provenances being pooled, at the different sites.

$\begin{array}{lll}\text { Lagnereau Truncat } & \text { Ruscas }\end{array}$

B2

$$
\begin{array}{ll}
\text { 1989, } 30 \text { April } & \text { 1989, } 2 \text { April } \\
\text { 1990, 22 April } & \text { 1990, 14 March }
\end{array}
$$

B3

$$
\text { 1989, } 13 \text { May }
$$$$
\text { 1990, } 7 \text { May }
$$

B4

$$
\begin{array}{ll}
\text { 1989, 19 May } & 1989,21 \text { April } \\
\text { 1990, 14 May } & 1990,3 \text { April }
\end{array}
$$

B5

1989, 22 May
1990, 18 May
1989, 12 April 1990, 21 March

1989, 4 May 1990, 16 April

$\begin{array}{ll}\text { 1988, 19 April } & \\ \text { 1989, 28 April } & \text { 1991, 12 May } \\ \text { 1990, 17 April } & \text { 1992, 14 May } \\ & \\ \text { 1988, 2 May } & \\ \text { 1989, 9 May } & \text { 1991, 22 May } \\ \text { 1990, 30 April } & \text { 1992, 18 May } \\ & \\ \text { 1988, 14 May } & \\ \text { 1989, 23 May } & \text { 1991, 1 June } \\ \text { 1990, 13 May } & \text { 1992, 25 May } \\ & \\ \text { 1988, 31 May } & \\ \text { 1989, 2 June } & \text { 1991, 12 June } \\ \text { 1990, 28 May } & \text { 1992, 29 May }\end{array}$

Results on coefficients of variation and standard errors of prediction of the different variables tested as predictors of phenological stages are presented in figure 3 . As similar trends were observed for all provenances, only mean values are presented. In preliminary calculations, $C V$ values using the sine curve reconstitution of daily temperatures were slightly higher than those obtained with the simpler formula $T m=(T \min +T \max ) / 2$. The latter formula was therefore used for the threshold study.
For the B2 stage, heat sums always presented a lower $C V$ than calendar days. For all stages, a regular decreasing trend of $C V$ was observed for threshold values decreasing from 5 to $0^{\circ} \mathrm{C}$. The heat sum calculated with a threshold value of $0^{\circ} \mathrm{C}$ gave a lower $C V$ than calendar days for all stages, except B5. Standard errors of prediction calculated for heat sums (with $T m=(T$ min + Tmax)/2) were always much lower than for calendar days, the difference being maximum for the B2 stage (about $9 \mathrm{~d}$ ). Very little
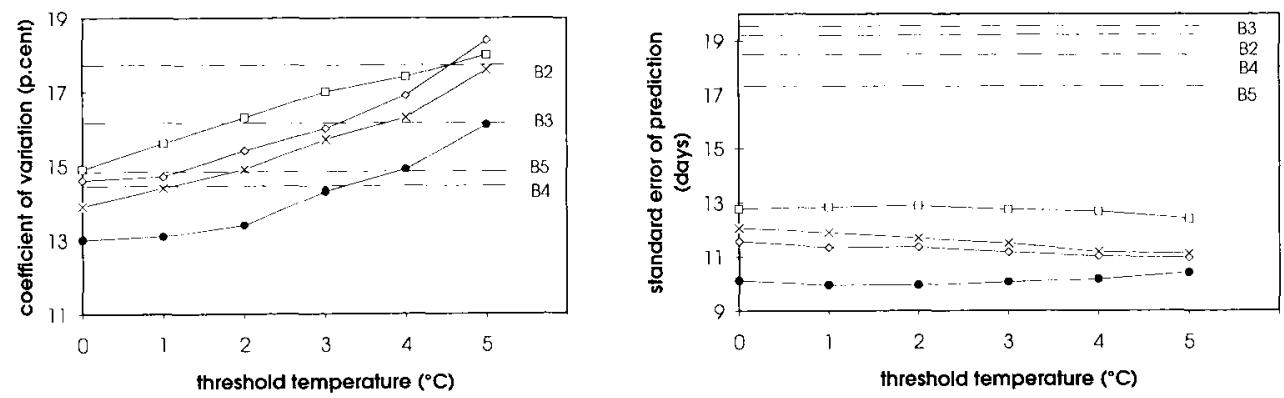

Fig 3. Coefficients of variation and standard errors of prediction obtained for heat sums at the onset of phenological stages from B2 to B5 in relation to threshold temperature and in comparison with values obtained for calendar days (----) (means for all provenances). B2: $-\mathrm{B} 3$ : $\diamond ; \mathrm{B} 4: \mathrm{x} ; \mathrm{B} 5: \square$. 
variation was observed in relation to threshold temperature values. From the above results, the heat sum calculated with $T m=$ $(T$ min $+T \max ) / 2$ and with a threshold value of $0^{\circ} \mathrm{C}$ was chosen as the best predictive variable for the onset of phenological stages and used for further analysis (expressed in degree-days above $0^{\circ} \mathrm{C}=D D_{0}$ ).

The heat sum means at the onset of the different stages for the 4 sites, all provenances being pooled, are presented in table IV. HS values per tree (all provenances and sites pooled together) reached at 2 different phenological stages within the same year were highly significantly correlated $(r=0.61$ to 0.92 , according to stage and year).

\section{Variation in phenology between maritime pine provenances}

An analysis of variance with $H S$ as the dependent variable was performed for each phenological stage. A general model with site, provenance (6 levels corresponding to the 6 geographic provenances), time (2 levels corresponding to the third and fourth year after plantation) and interaction effects was first tested. Adjusted sums of squares (type III of SAS) were used owing to the different numbers of unit plots at the 4 sites. These results are given in table V. For all phenological stages, provenance, site [provenance $x$ site] and [time $x$ site] effects were significant at the $5 \%$ level. HS values at the onset of the different phenological stages were always significantly lower at the Truncat and Orleans sites than at the Lagnereau and Ruscas sites (interactions with time or provenance did not affect this major distinction). A significant effect of time appeared only at the B3 and B4 stages with either no interaction or only a slightly significant interaction with provenance. No definite trend was observed between successive years.

Owing to the significant [provenance $x$ site] effect, and also to include [Corsica $x$

Table IV. Mean HS values, all provenances being pooled, at the onset of phenological stages (in degree-days above $0^{\circ} \mathrm{C}$ ) for each site.

Lagnereau Truncat Ruscas Orleans Generalmean

B2

$\begin{array}{lll} & & 1037 \\ 1065 & 843 & 1044 \\ 1126 & 782 & 1016\end{array}$

B3

B4

$1330 \quad 1071$

B5

$\begin{array}{ll}1418 & 1246 \\ 1525 & 1162\end{array}$




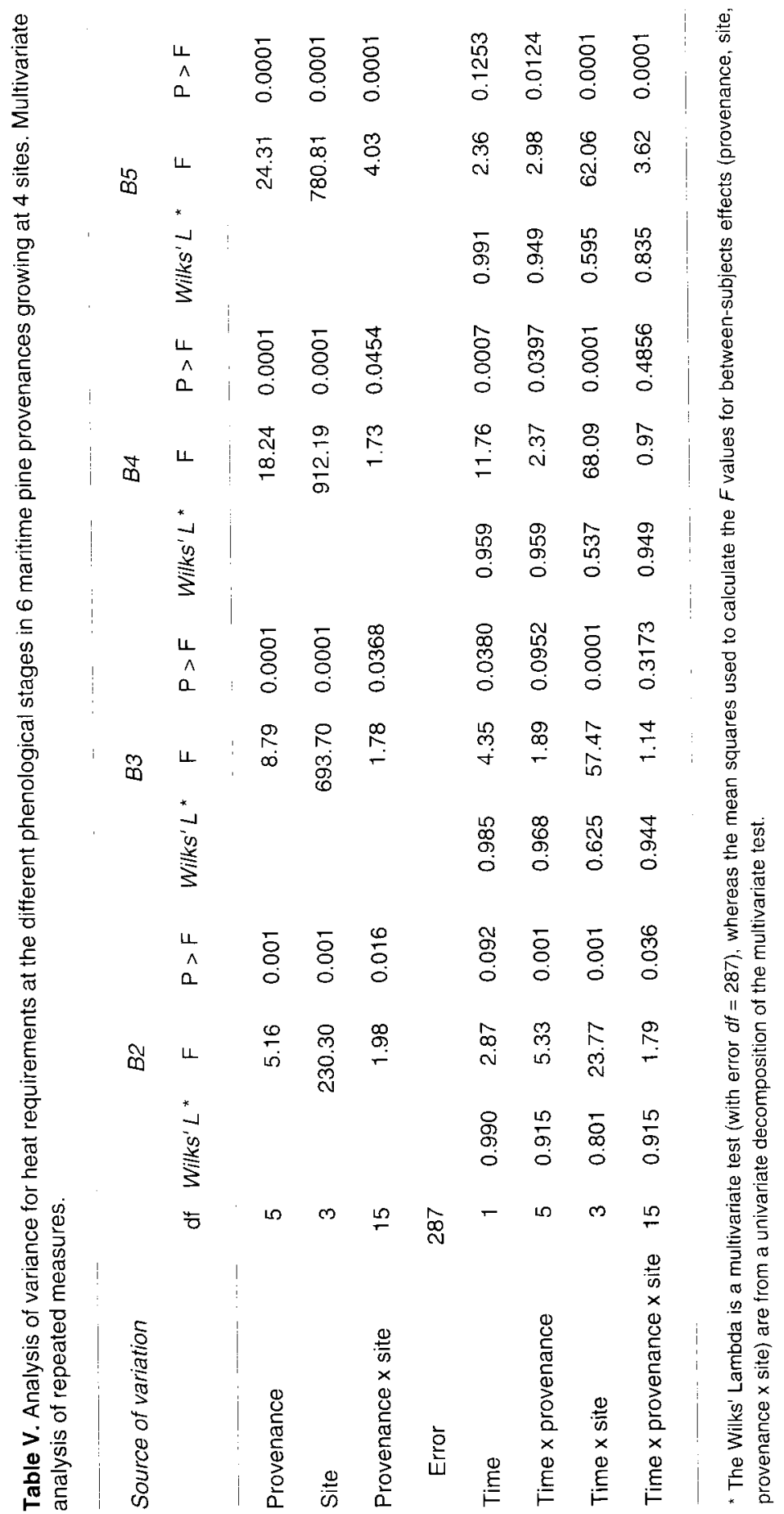


Landes] hybrids, an analysis of variance was then performed for each site with a restricted model without site and [site $x$ other sources] effects. A significant provenance effect was observed in 22 out of the 36 [site $x$ year $x$ stage] analyses (table $\mathrm{VI}$ ). $\mathrm{A}$ few [year $x$ site] combinations did not allow a discrimination between provenances, mainly in 1990 at the Truncat site and in 1991 at the Orleans site. In most cases with a provenance effect (19 out of 22), the Tamjout provenance exhibited a significantly higher precocity (ie lower heat sum values) than the Leiria provenance, the other provenances being intermediate (same results obtained with Student Newman Keuls, Scheffe's and Tukey's tests). The [Corsica $x$ Landes] hybrid always fell within the same homogeneous group as its parent populations. In order to generate data for all sites, years and stages, the provenance means (in $D D_{0}$ ) for each analysis were replaced by the difference with the overall mean for all provenances. The mean of these deviations was then calculated for each provenance ( $c f$ table VII). The earliness of the Tamjout provenance was clearly indicated by a large negative deviation in $D D_{0}$ from the mean of provenances. The Leiria provenance exhib- ited a contrasting behaviour with a delay of about $100 D D_{0}$ as compared to Tamjout. Other provenances showed an intermediate behaviour. The [Corsica $x$ Landes] hybrid appeared to show lower heat requirements, on average, than its 2 parent populations.

\section{Relation between phenology and shoot elongation}

For all pairs of shoot length measurements on a single tree, at 2 different dates within the same year, highly significant correlations were observed $(r=0.6-0.99)$. The last measurement of length (when most pines had reached the B5 stage) was considered further for the study of the relations between phenology and shoot growth. It was shown to be highly correlated with tree height $(r=$ 0.73 and 0.67 for 1989 and 1990 , respectively) at the Ruscas site, where these data were available.

A significant effect of provenance for shoot length was observed only at the Lagnereau site (results not shown), the Leiria provenance presented the lowest growth for both years. Significant differences

Table VI. Provenance effects for heat requirements in the analysis of variance performed for each site.

\begin{tabular}{rrrrrrrrr} 
Lagnereau & \multicolumn{2}{c}{ Truncat } & \multicolumn{3}{c}{ Ruscas } & \multicolumn{2}{c}{ Orleans } \\
\cline { 3 - 5 } & & & & & & & \\
1989 & 1990 & 1989 & 1990 & 1988 & 1989 & 1990 & 1991 & 1992
\end{tabular}

$\begin{array}{llllllllll}\mathrm{B} 2 & + & - & - & - & + & + & - & - & + \\ \mathrm{B} 3 & + & + & + & - & + & + & - & - & + \\ \mathrm{B} 4 & + & + & + & - & + & + & + & - & - \\ \mathrm{B} 5 & + & + & + & - & - & + & + & - & +\end{array}$

+ Indicates significant differences between provenances at the $5 \%$ level; - indicates no significant differences between provenances at the $5 \%$ level. 
Table VII. General comparison of maritime pine provenances for heat requirements, all phenological stages being considered together.

At all sites Orleans, Ruscas, Truncat

$\begin{array}{lrr}\text { Tamjout } & -54.8 & -46.0 \\ \text { Esterel } & -4.2 & -7.9 \\ \text { Cuenca } & -4.1 & -7.7 \\ \text { Landes x Vivario } & & -0.6 \\ \text { Landes } & +4.0 & +9.0 \\ \text { Vivario } & +13.5 & +12.8 \\ \text { Leiria } & +44.5 & +40.0\end{array}$

Values indicate the mean deviation of each provenance to the mean for all provenances, in degree-days above $0^{\circ} \mathrm{C}$.

between sites were apparent, pines in the Truncat and Orleans sites showing poor growth (approximately $10 \mathrm{~cm}$ for the last measure of shoot length for both years) compared with the Lagnereau site (approximately $20 \mathrm{~cm}$ ) and more so the Ruscas $(30-50 \mathrm{~cm})$ site.

Within each site, the HS accumulated at each phenological stage were negatively correlated with shoot length for the same year, ie the more vigorous trees had an earlier development (table VIII). Similar trends were observed for each provenance in the Lagnereau and Ruscas experiments and more variation between provenances was observed in the Orleans and Truncat experiments. An analysis of covariance was thus performed for the first 2 sites, for each phenological stage, with $H S$ as the dependent variable, provenance as the independent variable and shoot length as the covariable. Provenance effects observed in the analysis of variance (table VI) were always maintained after adjustment with the covariable. Tamjout and Leiria remained the earliest and latest provenances, respectively. Rankings of intermediate provenances were weakly affected.
Table VIII. Linear correlations between heat requirements and shoot length for the different phenological stages.

\section{Lagnereau Truncat Ruscas Orleans}

\begin{tabular}{|c|c|c|c|c|}
\hline B2 & $\begin{array}{l}-0.73^{\star \star} \\
-0.58^{\star \star}\end{array}$ & $\begin{array}{l}-0.50^{* *} \\
-0.37^{* *}\end{array}$ & $\begin{array}{l}-0.48^{\star \star} \\
-0.54^{\star *}\end{array}$ & $\begin{array}{l}-0.40^{\star \star} \\
-0.19^{* \star}\end{array}$ \\
\hline & & & $\begin{array}{l}-0.08 \mathrm{~ns} \\
-0.09 \mathrm{~ns}\end{array}$ & \\
\hline & $\begin{array}{l}-0.43^{* *} \\
-0.39^{* *}\end{array}$ & $\begin{array}{l}-0.35^{* *} \\
-0.39^{* *}\end{array}$ & $\begin{array}{l}-0.13^{\star} \\
-0.21^{* *}\end{array}$ & $\begin{array}{l}-0.5 \\
-0.2\end{array}$ \\
\hline & -0.3 & $\begin{array}{l}-0.37^{* *} \\
-0.36^{* *}\end{array}$ & $\begin{array}{l}-0.04 \text { ns } \\
-0.15^{\star \star}\end{array}$ & \\
\hline
\end{tabular}

Each line corresponds to years of observations (1989 and 1990 at the first 3 sites, 1991 and 1992 at the Orleans site); ${ }^{*}$ denotes a significant correlation at the $5 \%$ level; ${ }^{* *}$ denotes a significant correlation at the $1 \%$ level; ns denotes a non-significant correlation.

\section{Rust phenology - variation in the timing of susceptibility between 3 provenances at the Lagnereau site}

Periods of potential basidiospore dispersal (ie from the date of maximum production to the date of the end of production under optimal conditions) occurred throughout April for both years and sites: April 4-17, 1989 and April 5-23, 1990 at the Truncat site; April 4-24, 1989 and April 5-23, 1990 at the Lagnereau site.

The evolution of susceptibility, expressed as infection percentage after artificial inoculation, of the Corsican, Moroccan and Landes provenances for spring 1989 and 1990 is presented in figure 4, where potential basidiospore dispersal is also shown. Only the Moroccan provenance in 1989 appeared to show a significant degree of susceptibility before the end of the basidiospore production period. For both years, the 3 provenances did not differ significantly in their overall susceptibility throughout 

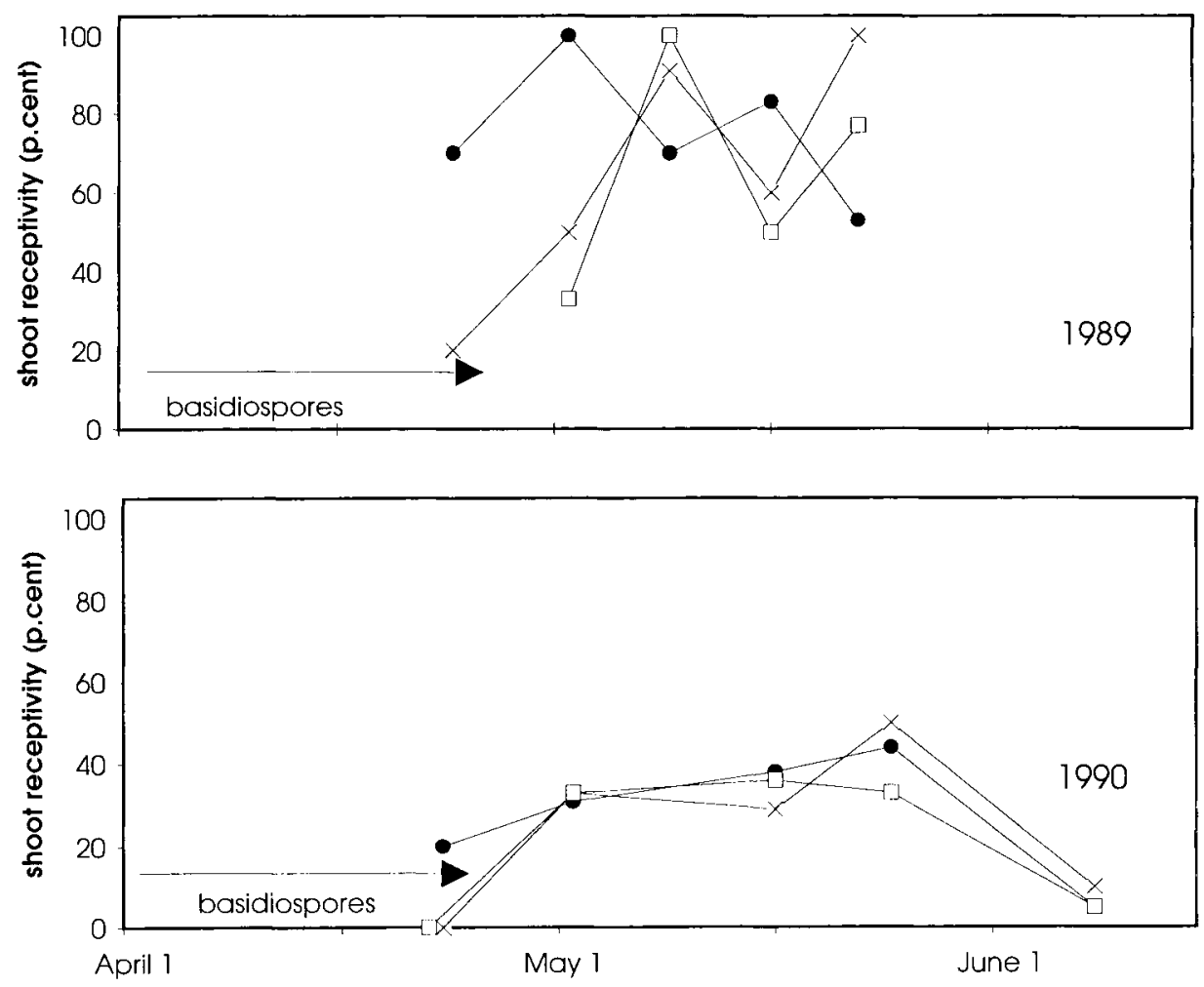

Fig 4. Evolution of shoot susceptibility to rust estimated after artificial inoculation of maritime pines from 3 different provenances and grown at the Lagnereau site (- represents the period of potential basidiospore dispersal). Landes: $\mathrm{x}$; Tamjout: $\mathbf{\bullet}$; Vivario: $\sqcup$.

Table IX. Maximum-likelihood 'analysis of variance' table for infection percentages of 3 maritime pine provenances grown at the Lagnereau site and artificially inoculated on 5 dates in spring 1989 and 1990.

Source *

1989

1990 df

Provenance $\mathrm{x}$ infection

Date $x$ infection

Provenance $x$ date $x$ infection

Provenance $x$ infection

Date $x$ infection

Provenance $x$ date $x$ infection chi-square

1.24

11.28

33.56

0.60

21.46

4.48
Prob

0.5371

0.0235

0.0000

$\begin{array}{rrr}2 & 0.60 & 0.7415 \\ 4 & 21.46 & 0.0003 \\ 8 & 4.48 & 0.8111\end{array}$

Only first and second order interactions with infection, and the corresponding chi-square tests for dependence between this variable and those included in the interactions are presented. 
spring (table IX). However, the significant [provenance $x$ date] effect in 1989 indicated a difference in the timing of susceptibility between the 3 provenances. This was mainly due to the earlier receptivity of the Moroccan provenance compared with the other 2 provenances. Differences in infection percentages were highly significant in 1989 for the 2 first observation dates, though this was not the case in 1990 .

\section{DISCUSSION}

Our results have defined the phenological development of maritime pine. In agreement with previous work on other species (Perala, 1985; Ramesh and Gopalaswamy, 1991), air temperature degree-days were shown to have a better predictive value of the onset of phenological stages, particularly the earlier ones, than calendar days. The accuracy of prediction was increased by approximately $50 \%$ for the B2 stage, from $19 \mathrm{~d}$, with calendar days as predictor, to $10 \mathrm{~d}$, with $H S$. This is most interesting from an epidemiological point of view as the B2 stage corresponds to the beginning of pine susceptibility to twisting rust (Desprez-Loustau, 1990). The lower adequacy of $H S$ in predicting later stages may be partly artefactual, arising from an increase in the error on HS calculations with time, related to seasonal warming, whereas the error on calendar days remains constant (weekly observations). The threshold temperature of $0^{\circ} \mathrm{C}$ has been chosen for statistical considerations though its biological significance is unknown. This value is lower than those commonly found in literature concerning pine shoot elongation and may be partly related to the fact that we studied earlier stages (Castonguay et al, 1984).

However, differences were still observed between sites, and to a much lesser extent between years, when considering $H S$ at the occurrence of phenological stages. This could account for factors other than air temperature which have not been included in the model. Soil temperature may be a better predictor of shoot growth than air temperature (Lavender, 1980). Soil water potential has been shown to be a contributing factor in red pine shoot growth (Jones et al, 1991). Site effects may also result in part from differences in the accuracy of weather station data in reflecting the experimental site microclimate. HS for the Orleans and Truncat sites may have been underestimated owing to their particular location (ie a forest clearing in the former and a coastal dune in the latter case). In addition, there was no clearance of the indigenous vegetation at these 2 sites, with a consequence that the proliferation of blackberry bushes may have provided shelter for the pines. Finally, the Orleans and Truncat sites appeared to be inferior sites for pine growth, probably due to sub-optimal soil conditions, possibly combined with the presence of blackberry bushes (competition effects for nutrients and/or water). The interaction of water stress and plant phenology has been emphasized by idso et al (1978). Water stress has been shown to result in earlier flushing in young Cedrus saplings (Finkelstein, 1981). Results obtained at the Lagnereau and Ruscas sites are possibly more representative of the average behaviour of maritime pine under silvicultural conditions. With a view to predicting the phenological stages, the aforementioned factors should be taken into account. The number of observation years employed was too few for detecting any age effect, though it is likely that this effect occurs, as mentioned for other species (Nienstaedt, 1974).

The demonstration of a variation in phenology between maritime pine provenances confirms earlier results (Desprez-Loustau and Baradat, 1991). The Tamjout provenance appears to require significantly lower $H S$ than the Leiria provenance to complete the early stages of growth. Other prove- 
nances were found to be intermediate, but might have been better discriminated with a more precise notation of phenological stages, on bi-weekly basis for example. This study also confirms that the precocity of the inter-provenance hybrid is greater than that of its parent populations. The provenance effect for phenology is not a result of differences in vigour, as evidenced by the covariance analysis. However, differences between provenances were less often observed at the inferior sites.

In contrast to pine phenological data, the same period of $M$ pinitorqua basidiospore production was observed at the 2 Landes sites and for the 2 years of observation, suggesting that pine and rust phenologies are driven by different factors. This resulted in a variation of pine-rust synchrony between sites and years. At the Lagnereau site, for both years of observation, shoot elongation, on average for all provenances, took place when basidiospores were no longer produced. This was also observed for the local (Landes) provenance. The earlier development of the Tamjout provenance resulted in a higher susceptibility to rust than the other provenances at the time when basidiospores were still being released. This is in agreement with previous data from another Landes site where the higher field susceptibility of the Tamjout provenance was though to be due to its higher precocity (Desprez-Loustau and Baradat, 1991).

The observation that shoot susceptibility in the Landes provenance was out of phase with the basidiospore production period in the same area for the 2 years of the study, is remarkable. This observation is in agreement with most of our data for the Landes area, where $M$ pinitorqua basidiospores are often produced before or at the very beginning of maritime pine shoot susceptibility (unpublished results). This may explain the very irregular pattern of rust damage in the area between years and sites. The 'rust explosions' observed in some years may be the result of a good synchrony between host and parasite phenologies due to particular weather conditions. The importance of pine phenology in relation to $M$ pinotorqua infection has also been emphasized in the case of $P$ nigra (Longo et al, $1970,1980)$. In contrast to maritime pine, $M$ pinitorqua appears better adapted to the $P$ sylvestris host. In $P$ sylvestris, annual variations in infection were attributed mainly to climatic conditions during pine growth; synchrony between host and parasite phenologies is generally observed (Kurkela, 1973). As previously hypothesized by Moriondo (1957) considering the occurrence of $M$ pinitorqua in Italy, this fungus, which is better adapted to rather cold climates, may have moved from northern to southern Europe during the glaciary and postglaciary periods, in association with $P$ sylvestris. It may then have passed to other susceptible pine species such as $P$ pinaster. Indeed, $P$ pinaster is thought to have appeared in the northern Landes area approximately 8000 years ago, at a time when $P$ sylvestris was the dominant species (Baradat and Marpeau-Bezard, 1988). The presence of $M$ pinitorqua in the Landes area may therefore represent a relic of this period, which may explain the partial lack of adaptation to present climatic conditions. Synchronization of the $M$ pinitorqua life cycle with that of pine is not critical for the survival of this rust as it can maintain itself upon the telial host (ie aspen). Moreover, pine infection can occur over a much longer period on seedlings and young saplings, with a free growth pattern, which are susceptible during all the growing season. Rust synchronization with maritime pine phenology, therefore, may not have been subjected to a high selection pressure. In contrast with the maritime pine-rust system, a good synchronization between host and parasite phenologies has been reported for other pine rusts (Merrill and Kistler, 1976; Hollis and Schmidt, 1977), which may reflect a longer coevolution process. Synchronization with 
the host plant has also been shown to be critical, and of great evolutionary significance, for several phytophagous insects, especially those which feed on newly emerged foliage (Du Merle, 1983, 1988; Hunter, 1992).

Overall, this study has emphasized the link between maritime pine phenology and predisposition to rust infections.

1. Annual and spatial variations in rust infection on maritime pines are likely to result mainly from differences in synchrony between host and parasite, resulting from weather (and microclimatological) conditions. Changes in climate, such as warming, may affect pine-rust synchrony, as predicted for plant-insect interactions (Dewar and Watt, 1992). Modelling of pine and rust phenologies with respect to climatological factors is essential in order to predict spatiotemporal patterns of infection risks.

2. Differences in precocity between genotypes may result in differences in predisposition to infection. Changes in vigour (higher growth) may also affect the infection risk in relation to higher precocity. This factor should be taken into account in maritime pine breeding. Selection for higher growth has been shown to result in earlier flushing in several species (Kleinschmit and Sauer, 1976; Rehfeldt, 1992). Fertilization effects should also be considered.

\section{ACKNOWLEDGMENTS}

We thank the technical staff of INRA Experimental Stations at Le Ruscas, Orleans and Bordeaux, especially $D$ Vauthier, $M$ Vallance and $P$ Paztuzka, for their technical assistace; $\mathrm{H}$ Jactel and A Kremer for their helpful comments on the manuscript; and $\mathrm{M}$ Guye for reviewing the English.

\section{REFERENCES}

Baradat P, Marpeau-Bezard A (1988) Le pin maritime Pinus pinaster Ait. Biologie et génétique des ter- pènes pour la connaissance et l'amélioration de l'espèce. Thèse d'Etat de I'Université Bordeaux I, France

Cannell GR, Smith RI (1983) Thermal time, chill days and prediction of budburst in Picea sitchensis. J App/ Ecol 20, 951-963

Cannell GR, Thompson S, Lines R (1976) An analysis of inherent differences in shoot growth within some north temperate conifers. In: Tree Physiology and Yield Improvement (MGR Cannell, FT Last, eds) Academic Press, New York, USA

Castonguay $Y$, Boisvert J, Dubé PA (1984) Comparaison de techniques statistiques utilisées dans l'élaboration de modèles prévisionnels phénoclimatiques. Agric For Meteoro/ 31, 273-288

Debazac EF (1966) Les modalités de la croissance en hauteur chez les pins. Bull Soc Bot Fr, 3-14

Desprez-Loustau ML (1990) A cut-shoot bioassay for assessment of maritime pine susceptibility to twisting rust. Eur J For Pathol 20, 386-391

Desprez-Loustau ML, Baradat P (1991) Variabilité interraciale de la sensibilité à la rouille courbeuse chez le pin maritime. Ann Sci For 48, 497-511

Desprez-Loustau ML, Dupuis F (1992) A time-course study of teliospore germination and basidiospore release in Melampsora pinitorqua. Mycol Res 96 , 442-446

Dewar RC, Watt AD (1992) Predicted changes in the synchrony of larval emergence and budburst under climatic warming. Oecologia 89, 557-559

Du Merle P (1983) Phénologies comparées du chêne pubescent, du chêne vert et de Tortrix viridana $L$ (Lep Tortricidae). Mise en évidence chez l'insecte de deux populations sympatriques adaptées chacune à l'un des chênes. Acta $C E c o l$ OEcol Applic 4, 5574

Du Merle P (1988) Phenological resistance of oaks to the green oak leafroller, Tortrix viridana $\mathrm{L}$ (Lep Tortricidae). In: Mechanisms of Woody Plant Defenses against Insects - Search for Pattern (WJ Mattson, J Levieux, C Bernard-Dagan, eds) Springer-Verlag, New York, USA, 215-226

Finkelstein D (1981) Influence des conditions d'alimentation hydrique sur le débourrement et la croissance des jeunes plants de Cèdre (Cedrus atlantica Manetti) cultivés en serre. Ann Sci For 38, 513-530

Hollis CA, Schmidt RA (1977) Site factors related to fusiform rust incidence in north Florida slash pine plantations. For Sci 23, 69-77

Hunter MD (1992) A variable plant-insect interaction: the relationship between tree budburst phenology and population levels of insect herbivores among trees. Ecol Entomol 16, 91-95

Idso SB, Jackson RD, Reginato RJ (1978) Extending the 'degree day' concept of plant phenological development to include water stress effects. Ecology 59 , $431-433$ 
Illy G, Castaing JP (1968) Rythme saisonnier de la croissance en diamètre et en hauteur chez le pin maritime. Bull Soc Bot Fr 173-179

Jones EA, Reed DD, Cattelino PJ, Mroz GD (1991) Seasonal shoot growth of planted red pine predicted from air temperature degree days and soil water potential. For Ecol Manage 46, 201-214

Kleinschmit J, Sauer A (1976) Variation in morphology, phenology and nutrient content among Picea abies clones and provenances, and its implications for tree improvement. In: Tree Physiology and Yield Improvement (MGR Cannell, FT Last, eds) Academic Press, New York, 503-517

Kremer A (1982) Déterminisme génétique de la croissance en hauteur du pin maritime (Pinus pinaster Ait). 1. Rôle du polycyclisme. Ann Sci For 38, 199222

Kremer A, Roussel G (1982) Composantes de la croissance en hauteur du pin maritime (Pinus pinaster Ait). Ann Sci For 39, 77-98

Kremer A, Roussel G (1986) Décomposition de la croissance en hauteur du pin maritime (Pinus pinaster Ait). Variabilité géographique des composantes morphogénétiques et phénologiques. Ann Sci For 43 , 15-34

Kremer A, Lascoux M (1987) Genetic architecture of height growth in maritime pine. Silvae Genet 37, 1 8

Kurkela T (1973) Epiphytology of Melampsora rusts of Scots pine (Pinus sylvestris $L$ ) and aspen (Populus tremula L). Comm Inst For Fenn 79, 1-68

Lanner (1976) Patterns of shoot development in Pinus and their relationship to growth potential. In: Tree Physiology and Yield Improvement (MGR Cannell, FT Last, eds), Academic Press, New York, USA, 503-517

Lavender DP (1980) Effects of the environment upon the shoot growth of woody plants. In: Proc IUFRO Meeting 'Control of shoot growth in trees', July 20-24, Fredericton, Canada (CHA Little, ed), 76-106
Longo N, Moriondo F, Naldini BM (1970) Biologia ed epidemiologia di Melampsora pinitorqua Rostr. Ann Accad it Sc For XIX, 83-175

Longo N, Moriondo F, Naldini-Longo BM (1980) Some aspects of biology of Melampsora pinitorqua Rostr in Italy, also compared to other European countries. Phytopath Medit 19, 30-34

Merrill W, Kistler BR (1976) Phenology and control of Endocronartium harknesii in Pennsylvania. Phytopathology $66,1246-1248$

Moriondo F (1957) Osservazioni sulla diffusione della ruggine curvatrice del pino in Italia. La Ricerca Scientifica 27, 405-411

Moser EB, Saxton AM, Pezeshki SR (1990) Repeated measures analysis of variance: application to tree research. Can J For Res 20, 524-535

Nienstaedt H (1974) Genetica variation in some phenological characteristics of forest trees. In: Phenology and Seasonality Modelling ( $\mathrm{H}$ Lieth, ed) Springer Verlag, 389-400

Osawa A, Shoemaker CA, Stedinger JR (1983) A stochastic model of balsam fir bud phenology utilizing maximum likelihood parameter estimation. For Sci $29,478-490$

Perala DA (1985) Predicting red pine shoot growth using growing degree days. For Sci 31, 913-625

Ramesh P, Gopalaswamy N (1991) Heat unit requirement and prediction of developmental stages in soybean. J Agron Crop Sci 167, 236-240

Rehfeldt GE (1992) Early selection in Pinus ponderosa: compromises between growth potential and growth rhythm in developing breeding strategies. For $\mathrm{Sci}$ $38,661-677$

SAS Institute Inc (1988) SAS/STAT User's Guide. Release 6.03 edition. SAS Institute Inc, Cary, NC, USA

Volney WJA, Cerezke HF (1992) The phenology of white spruce and the spuce budworm in northern Alberta. Can J For Res 22, 198-205 